\title{
ALAT UJI VISKOSITAS BIODIESEL DARI MINYAK GORENG BEKAS BERBASIS TEKNOLOGI INFRARED
}

\author{
Khairul Muhammad*), Anton Yudhana \\ Program Studi Teknik Elektro, Fakultas Teknologi Industri, Universitas Ahmad Dahlan \\ Kampus IV, Jln. Ring Road Selatan, Tamanan, Banguntapan, Bantul, Yogyakarta 55166 \\ ${ }^{*}$ E-mail:khairul1400022030@webmail.uad.ac.id
}

\begin{abstract}
Abstrak
Alat uji viskositas dalam penelitian ini adalah suatu teknologi infrared untuk menguji tingkat kekentalan minyak biodiesel. Penelitian ini difokuskan untuk menguji biodiesel dari minyak goreng bekas. Telah berhasil dirancang alat uji viskositas dengan memanfaatkan teknologi infrared. Sensor infrared menggunakan LED photodiode dan bagian board microcontroller menggunakan Atmega 328. Sensor infrared berfungsi untuk mendeteksi lewatnya kelereng di dalam tabung yang selanjutya dijadikan rujukan untuk mendapatkan nilai waktu tempuhnya. Metode yang digunakan pada pengujian viskositas ini adalah metode jatuhan kelereng ke dalam minyak. Kelereng dimasukkan ke dalam tabung yang berisi minyak dan dihitung waktu tempuh kelereng sampai ke dasar tabung. Tujuan alat ini dirancang untuk mempermudah dalam perhitungan waktu tempuh yang selama ini dengan cara manual memanfaatkan stopwatch Waktu tempuh yang didapatkan tersebut menjadi dasar untuk penghitungan viskositas minyak. Pengambilan data dilakukan dengan menggunakan tiga sampel biodiesel dari minyak yang berbeda. Ketiga minyak tersebut adalah biodiesel minyak kelapa, biodiesel minyak goreng, dan biodiesel minyak jelantah, dengan jumlah pengujian masing-masing sebanyak 20 kali. Hasil penelitian menunjukkan bahwa nilai viskositas dengan sampel biodiesel minyak kelapa 0,0044398 kg/m.s, sampel biodiesel minyak goreng $0,035651 \mathrm{~kg} / \mathrm{m} . \mathrm{s}$, dan biodiesel minyak jelantah $0,05302 \mathrm{~kg} / \mathrm{m} . \mathrm{s}$. Perbandingan akhir dengan perhitungan secara manual telah didapatkan didapatkan rata-rata kesalahan relatif sebesar 4,76\%.
\end{abstract}

Kata kunci: viskositas, sensor infrared, arduino uno, biodiesel.

\begin{abstract}
The tool in this study is an infrared technology to test the level of viscosity of biodiesel oil. This research is focused on testing biodiesel from used cooking oil. Viscosity test equipment has been successfully designed by using infrared technology. The infrared sensor uses a photodiode LED and the type of microcontroller was Atmega 328. The infrared sensor functions to detect the passage of marbles in the tube which is then used as a reference to get the time value. The method used in this viscosity test is duration of falling marbles into oil. Marbles are put into a tube containing oil and taken to the bottom of the tube. The purpose of this tool is designed to facilitate the calculation of the falling duration that has been done manually by using a stopwatch. The falling duration obtained is the basis for calculating oil viscosity. Data was collected using three samples of biodiesel from different oils. The three oils are coconut oil, cooking oil, and used cooking oil, with number of measurement 20 times each. The results showed that the viscosity value of the coconut oil sample was $0.0044398 \mathrm{~kg} / \mathrm{m} . \mathrm{s}$, the cooking oil sample was $0.035651 \mathrm{~kg} / \mathrm{m} . \mathrm{s}$, and the used cooking oil was $0.05302 \mathrm{~kg}$ / m.s. The final comparison with manual calculations has been found to obtain an average relative error of $4.76 \%$.
\end{abstract}

Keywords: infrared sensors, Arduino Uno, biodiesel viscosity

\section{Pendahuluan}

Pembuatan Biodiesel dari minyak bekas telah dilakukan oleh [1] [2][3]. Pengujian kualitas biodiesel telah dilakukan dengan metode kimiawi [4][5][6]. Alat uji kualitas biodisel mempunyai banyak metode diantaranya dengan menguji tingkat kekentalan atau nilai viskositasnya. Pengujian viskositas telah dilakukan oleh [7] denga karakter citranya. Sedangkan pengujian yang lain adalah [8][9][10]. Pengujian viskositas dengan menggunakan jatuhan bola telah dilakukan oleh [11]. Pada penelitian-penelitian sebelumnya untuk uji viskositas biodiesel dilakukan dengan ultrasonic dan dengan metode optik. Pada penelitian kali ini uji viskositas dilakukan dengan mengembangkan metode yang telah dilakukan oleh [11] dengan melengkapi tampilan digitalnya.

Penelitian ini dilakukan dengan dengan merancang sebuah sistem menggunakan mikrokontroller dan infrared berfungsi untuk mendeteksi lewatnya kelereng di dalam 
tabung sehingga menghasilkan waktu stopwatch yang tampil pada layar lcd 16x2 untuk menentukan nilai viskositas.

\section{Metode}

Penelitian ini menggunakan komponen elektronika yang dapat digunakan untuk menghitung lamanya waktu kelereng jatuh ke dasar tabung yang berisi minyak diesel. Alat dan bahan yang digunakan adalah Ardiuno uno R3, Led infrared dan led photo diode, LCD 16x2, Power Supply, Minyak biodiesel, Arduino IDE 1.8.5, multimeter, solder, tenol, obeng, Laptop, kamera, Tabung kaca D 17 $\mathrm{mm}$ T $60 \mathrm{~cm}$ dan Kelereng D $10 \mathrm{~mm}$.

\subsection{Perancangan Perangkat Keras}

Perancangan perangkat keras dimaksudkan agar sistem bisa bekerja sesuai yang diharapkan dan dapat berjalan dengan baik. Tahap perancangan ini menggunakan sensor Infrared, Arduino UNO, dan LCD. Diagram blok sistem dapat dilihat pada Gambar 1.

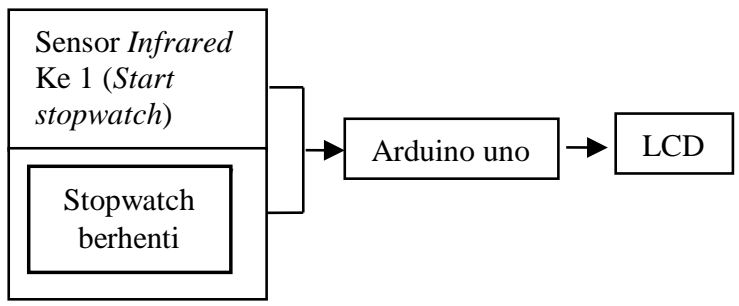

Gambar 1.Diagram Blok Sistem.

Gambar 1 menunjukkan tahap awal sebelum pemrosesan yang akan dilakukan adalah menjatuhkan kelereng yang berukuran diameter $2 \mathrm{~cm}$ kedalam tabung kaca setinggi 41 $\mathrm{cm}$ yang sudah berisikan minyak biodiesel. Ketika kelereng turun melewati sensor infrared yang pertama maka otomatis sensor infrared akan mendeteksi kelereng dan stopwatch aktif.

Pada saat kelereng melewati sensor infrared yang kedua, maka sensor infrared akan mendeteksi kelereng dan stopwatch berhenti/stop. Selanjutnya LCD menampilkan hasil stopwatch dan hasil perhitungan viskositas dari sampel biodiesel yang diuji.

\subsection{Perancangan Perangkat Lunak}

Perancangan perangkat lunak ini dimaksudkan untuk menghubungkan dengan hardware dan memastikan sistem bekerja sesuai dengan tujuan pengujian. Proses jalannya aplikasi digambarkan dengan diagram alir seperti yang ditunjukkan pada Gambar 2.

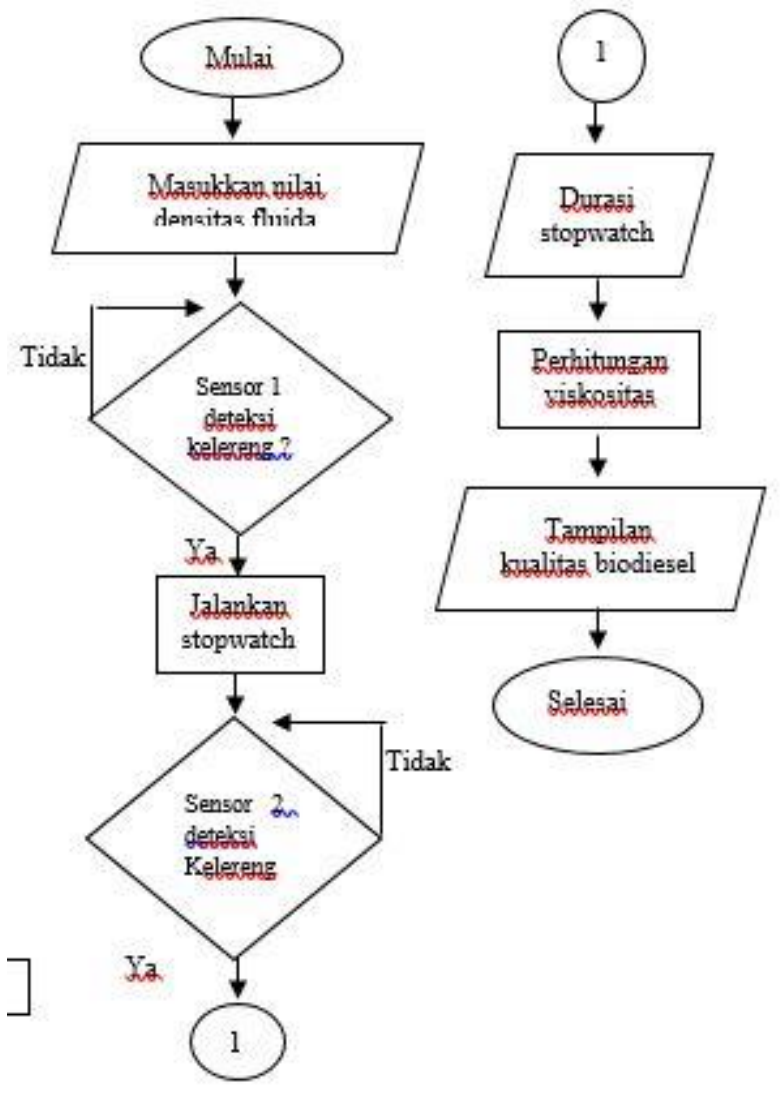

Gambar 2. Diagram Alir Sistem (flowchart).

Gambar 2 merupakan alur kerja dari alat uji viskositas biodiesel.

\subsection{Pengujian Sistem \\ 2.3.1. Pengujian Perangkat Keras}

Pengujian Perangkat Keras ini dimaksudkan untuk mengetahui hardware yang digunakan bekerja dengan baik atau tidak. Untuk mengetahuinya, maka perlu dilakukan serangkaian pengujian pada masing-masing hardware yang akan digunakan di dalam sistem tersebut. Dapat dilihat pada Gambar 3.Wiring alat.

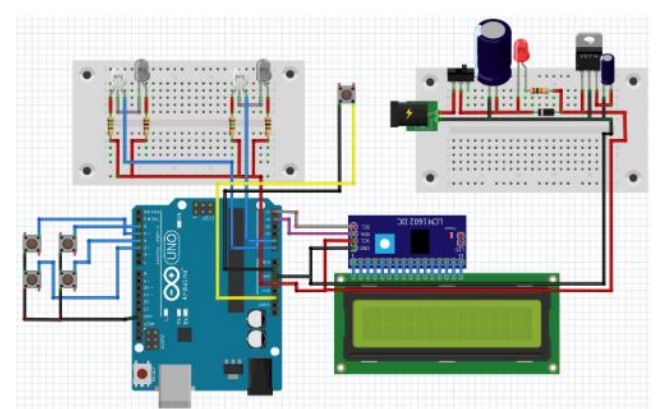

Gambar 3. Wiring Alat. 


\subsubsection{Pengujian Perangkat Lunak}

Pengujian ini dimaksudkan untuk meneliti dan menyusun listing pada software agar ketika didownload ke Arduino uno dapat bekerja dengan baik.

\section{Implementasi Sistem}

Alat uji viskositas ini dirancang menggunakan sensor photodiode atau biasa disebut sensor infrared. Prototype alat uji kualitas biodiesel dapat dilihat pada Gambar 4.

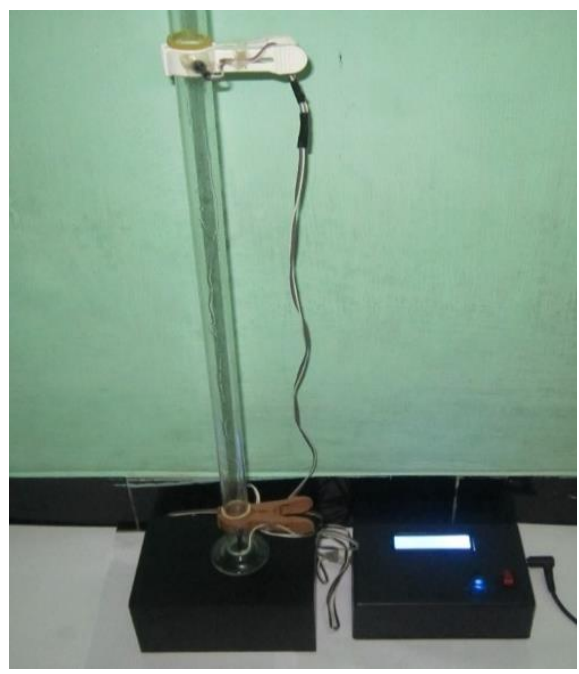

Gambar 4. Perangkat Keras Alat Uji Viskositas Biodiesel.

Gambar 4 menunjukkan bahwa alat uji viskositas ini menggunakan sensor yang menerima data dari kelereng yang dijatuhkan. Pada saat kelereng melewati sensor 1 maka stopwatch akan memulai menghitung dan saat kelereng melewati sensor 2 maka stopwatch akan berhenti. Waktu jatuhan didapat dari selisih dari waktu kelereng melewati sensor 2 dikurangi kelereng melewati sensor 1 . Selisih waktu yang didapat akan digunakan dalam rumus viskositas yang telah ada dalam program. Rumus penghitungan viskositas berdasar waktu jatuhan kelereng telah dilakukan oleh [7].

$$
\mu=\frac{\frac{4}{3} \pi r^{3}\left(\rho_{b}-\rho_{f}\right)}{6 \pi r v}=\frac{\frac{2}{9} r^{2} g\left(\rho_{b}-\rho_{f}\right)}{v}
$$

Keterangan:

$$
\begin{array}{ll}
\mu \quad=\text { viskositas } & \frac{4}{3} \pi r^{3}= \\
\text { volume bola } & \\
\rho_{b} \quad=\text { indensitasbola } & \rho_{f}= \\
\text { indensitas fluida } & \\
v \quad=\text { kecepatan } &
\end{array}
$$

\subsection{Pengujian Perangkat Keras}

Pengujian perangkat keras merupakan proses pengujian sistem untuk menentukan bahwa rancangan tersebut berjalan dengan baik. Pengujian perangkat keras dilakukan menggunakan fungsi stopwatch pada sensor infrared. Pengujian sensor infrared dilakukan dengan memberikan tegangan 5 VDC dari modul mikrokontroler.

\subsection{Pengujian Perangkat Lunak}

Pengujian sistem ini dilakukan untuk mengetahui program pada arduino bisa berjalan dengan baik. Proses pengujian ini dilakukan debugging program dan proses serial monitoring. Tahap pertama yang dilakukan yaitu proses debugging untuk melihat program dapat diupload ke mikrokontroller. Tahap kedua adalah proses serial monitoring pada Arduino IDE. Proses ini dilakukan untuk mengetahui nilai waktu tempuh kelereng didalam tabung yang hasilkan oleh sensor infrared. Proses upload program perangkat lunak dapat dilihat pada Gambar 5.

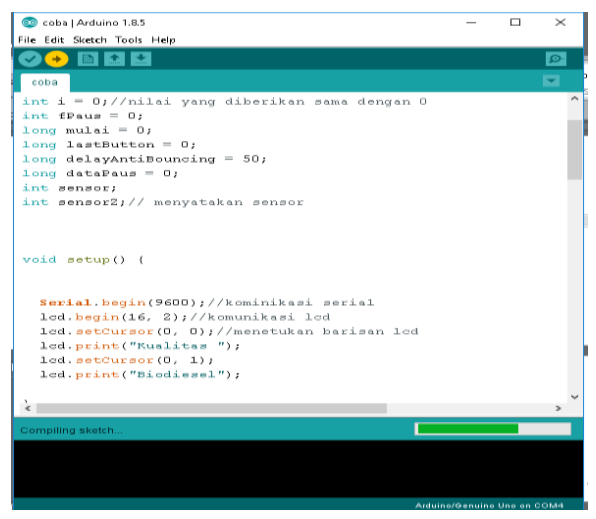

Gambar 5. Proses Upload Program

\subsection{Pengujian Viskositas Biodiesel Minyak Kelapa}

Data viskositas ini diperoleh melalui perhitungan menggunakan persamaan (1). Data viskositas dapat dilihat pada Tabel 1, dimana menunjukan perbedaan perhitungan secara manual dan perhitungan dari alat uji pada bis minyak kelapa.

Berdasarkan tabel yang diatas hasil rata-rata viskositas yang dihasilkan biodiesel minyak kelapa dengan melakukan 20 kali percobaan yaitu $0,044398 \mathrm{~kg} / \mathrm{m} . \mathrm{s}$, sedangkan hasil rata-rata viskositas secara perhitungan manual yaitu $0,045032 \mathrm{~kg} / \mathrm{m} . \mathrm{s}$, jadi kesalahan error yang didapat dari hasil rata-rata perhitungan secara manual dan perhitungan secara alat yaitu $1,41 \%$. Pada hasil standar daviasi secara perhitungan dengan 20 kali percobaan yaitu 0,002294 sedangkan hasil standar daviasi secara alat yaitu 0,002419 . Pada gambar dibawah ini menunjuk grafik perbandingan hasil viskositas perhitungan dan alat, dapat dilihat pada Gambar 6 . 
Tabel 1. Hasil Perbandingan Viskositas Minyak Kelapa.

\begin{tabular}{clll}
\hline \multirow{3}{*}{ Percobaan } & \multicolumn{2}{c}{$\begin{array}{c}\text { Data hasil viskositas kg/m.s } \\
\text { (Minyak kelapa) }\end{array}$} & Error $\%$ \\
\cline { 2 - 3 } & Perhitungan & Alat & \\
\hline 1. & 0,04512 & 0,04321 & $4,23 \%$ \\
2. & 0,04203 & 0,04124 & $1,87 \%$ \\
3. & 0,04242 & 0,04144 & $2,31 \%$ \\
4. & 0,04324 & 0,04240 & $1,94 \%$ \\
5. & 0,04679 & 0,04405 & $5,85 \%$ \\
6. & 0,04550 & 0,04401 & $3,27 \%$ \\
7. & 0,04430 & 0,04401 & $0,65 \%$ \\
8. & 0,04210 & 0,04190 & $0,47 \%$ \\
9. & 0,04914 & 0,04906 & $0,16 \%$ \\
10. & 0,04802 & 0,04704 & $2,04 \%$ \\
11. & 0,04810 & 0,04809 & $0,02 \%$ \\
12. & 0,04513 & 0,04421 & $2,03 \%$ \\
13. & 0,04302 & 0,04239 & $1,46 \%$ \\
14. & 0,04340 & 0,04280 & $1,38 \%$ \\
15. & 0,04604 & 0,04603 & $0,02 \%$ \\
16. & 0,04207 & 0,04203 & $0,09 \%$ \\
17. & 0,04298 & 0,04292 & $0,13 \%$ \\
18. & 0,04707 & 0,04701 & $0,12 \%$ \\
19. & 0,04707 & 0,04701 & $0,12 \%$ \\
20. & 0,04710 & 0,04709 & $0,02 \%$ \\
Rata-rata & 0,045032 & 0,044398 & 1,41 \\
Standar & 0,002294 & 0,002419 & 1,60 \\
deviasi & & & \\
\hline & & &
\end{tabular}

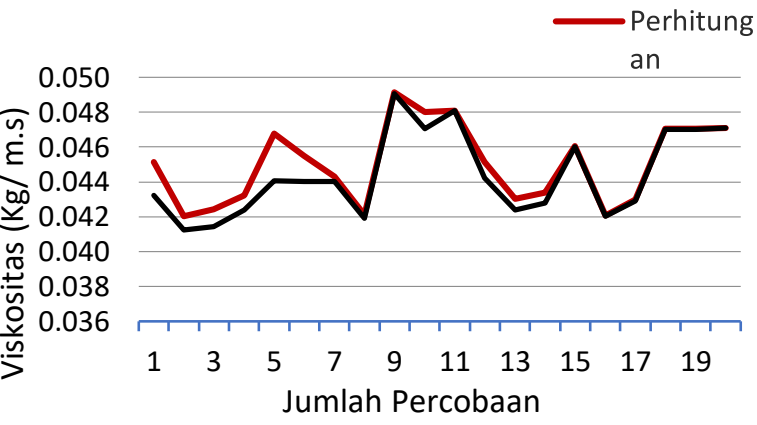

Gambar 6. Perbandingan Viskositas Perhitungan dan Alat pada Minyak Kelapa

\subsection{Pengujian Viskositas Biodiesel dari Minyak Jelantah}

Data viskositas ini diperoleh melalui perhitungan menggunakan persamaan (1). Data viskositas dapat dilihat pada Tabel 2, dimana menunjukan perbedaan perhitungan secara manual dan perhitungan dari alat uji pada biodiesel minyak jelantah.

Berdasarkan tabel yang diatas hasil rata-rata viskositas yang dihasilkan biodiesel minyak jelantah dengan melakukan 20 kali percobaan yaitu $0,05302 \mathrm{~kg} / \mathrm{m} . \mathrm{s}$, sedangkan hasil rata-rata viskositas secara perhitungan manual yaitu $0,05341 \mathrm{~kg} / \mathrm{m} . \mathrm{s}$, jadi kesalahan error yang didapat dari hasil rata-rata perhitungan secara manual dan perhitungan secara alat yaitu $0,73 \%$. Pada hasil standar daviasi secara perhitungan dengan 20 kali percobaan yaitu 0,000269 sedangkan hasil standar daviasi secara alat yaitu 0,000658. Pada gambar dibawah ini menunjuk grafik perbandingan hasil viskositas perhitungan dan alat, dapat dilihat pada Gambar 7.

Tabel 2. Hasil Perbandingan Viskositas Minyak Jelantah.

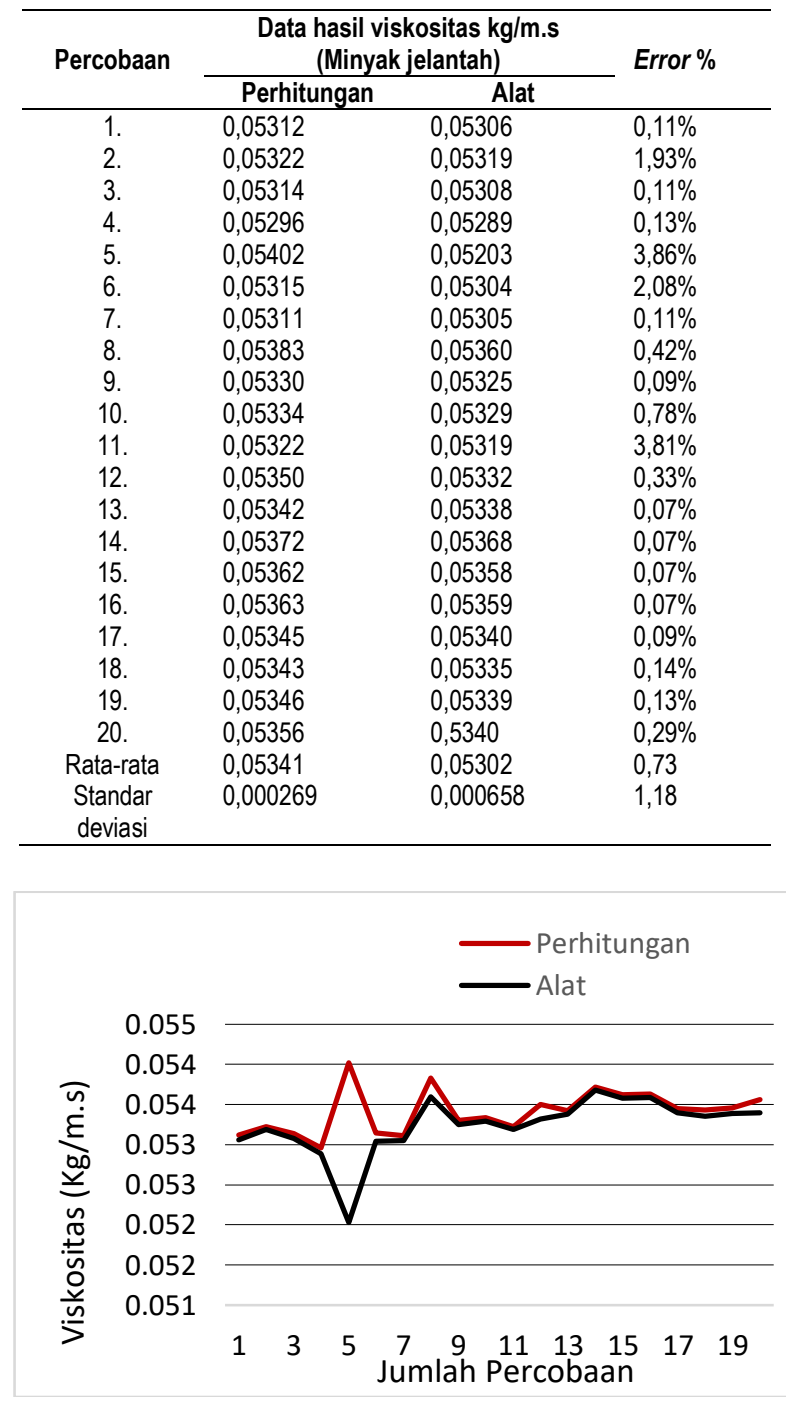

Gambar 7. Perbandingan Viskositas Perhitungan dan Alat pada Jelantah

\subsection{Pengujian Viskositas Biodiesel dari Minyak Goreng}

Data viskositas ini diperoleh melalui perhitungan menggunakan persamaan (1). Data viskositas dapat dilihat pada Tabel 3, dimana menunjukan perbedaanperhitungan secara manual dan perhitungan dari alat uji pada biodiesel minyak goreng.

Berdasarkan tabel yang diatas hasil rata-rata viskositas yang dihasilkan biodiesel minyak goreng dengan melakukan 20 kali percobaan yaitu $0,035651 \mathrm{~kg} / \mathrm{m} . \mathrm{s}$, sedangkan hasil rata-rata viskositas secara perhitungan manual yaitu $0,036001 \mathrm{~kg} / \mathrm{m} . \mathrm{s}$, jadi kesalahan error yang didapat dari hasil rata-rata perhitungan secara manual dan 
perhitungan secara alat yaitu $0,96 \%$. Pada hasil standar daviasi secara perhitungan dengan 20 kali percobaan yaitu 0,000477 sedangkan hasil standar daviasi secara alat yaitu 0,000505. Pada gambar dibawah ini menunjuk grafik perbandingan hasil viskositas perhitungan dan alat, dapat dilihat pada Gambar 8

Tebel 3. Hasil Perbandingan Viskositas Minyak Goreng.

\begin{tabular}{clll}
\hline \multirow{2}{*}{ Percobaan } & \multicolumn{2}{c}{$\begin{array}{c}\text { Data hasil viskositas kg/m.s } \\
\text { (Minyak goreng) }\end{array}$} & Error $\%$ \\
\cline { 2 - 3 } & Perhitungan & Alat & \\
\hline 1. & 0,03602 & 0,03521 & $2,24 \%$ \\
3. & 0,03612 & 0,03524 & $2,43 \%$ \\
4. & 0,03621 & 0,03504 & $3,23 \%$ \\
5. & 0,03624 & 0,03620 & $0,11 \%$ \\
6. & 0,03579 & 0,03574 & $0,13 \%$ \\
7. & 0,03650 & 0,03590 & $1,64 \%$ \\
8. & 0,03541 & 0,03530 & $0,31 \%$ \\
9. & 0,03510 & 0,03490 & $0,56 \%$ \\
10. & 0,03614 & 0,03606 & $0,22 \%$ \\
11. & 0,03640 & 0,03629 & $0,30 \%$ \\
12. & 0,03602 & 0,03521 & $0,24 \%$ \\
13. & 0,03579 & 0,03574 & $0,13 \%$ \\
14. & 0,03650 & 0,03590 & $1.64 \%$ \\
15. & 0,03540 & 0,03530 & $0,31 \%$ \\
16. & 0,03510 & 0,03490 & $0,56 \%$ \\
17. & 0,03579 & 0,03574 & $0,13 \%$ \\
18. & 0,03690 & 0,03641 & $1,32 \%$ \\
19. & 0,03611 & 0,03604 & $0,19 \%$ \\
20. & 0,03596 & 0,03540 & $1,55 \%$ \\
Rata-rata & 0,03651 & 0,03650 & $0,02 \%$ \\
Standar & 0,036001 & 0,035651 & 0,96 \\
deviasi & 0,000477 & 0,000505 & 0,98 \\
\hline & & & \\
\hline & & & \\
\hline
\end{tabular}

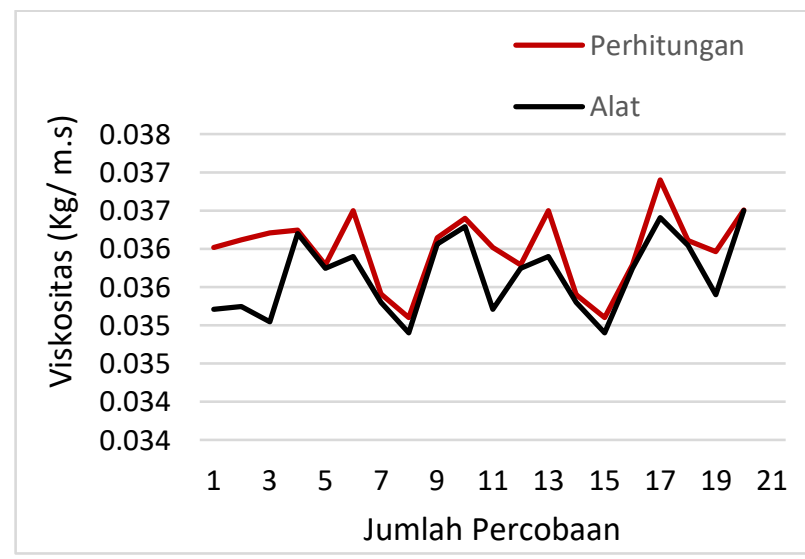

Gambar 8. Perbandingan Viskositas Perhitungan dan Alat pada Minyak Goreng

\section{Kesimpulan}

Telah berhasil dibuat alat uji viskositas biodiesel dari minyak goreng bekas berbasis teknologi infrared. Alat uji mampu menampilkan waktu jatuh kelereng sampai ke dasar tabung yang berkorelasi dengan nilai viskositas. Semakin lama waktu tempuh yang jatuhan kelereng maka semakin tinggi nilai viskositasnya dan sebaliknya.Alat uji viskositas ini dapat memberikan manfaat untuk memudahkan pengujian kualitas viskositas secara cepat dan akurat. Manfaat lain dari hasil penelitian ini adalah membantu mahasiswa khususnya teknik kimia dalam melakukan uji kualitas biodiesel yang selama ini masih dilakukan secara manual penghitungan waktunya dengan stop watch.

\section{Referensi}

[1]. I. W. Suirta, "Preparasi Biodiesel Dari Minyak Jelantah Kelapa Sawit,” J. Kim., vol. 3, no. 1, pp. 1-6, 2009.

[2]. H. . Syamsidar, "Pembuatan dan uji kualitas biodiesel dari minyak jelantah," pp. 209-218, 2010.

[3]. T. B. Ariani, Farida, Ginting, Elizabet, Sitorus, "Karakteristik Pengaruh Biodiesel Dari Limbah Sawit Cair Terhadap Unjuk Kerja Mesin Diesel Empat Langkah," J. Pendidik. Teknol. dan Kejuru., vol. 02, no. 16, pp. 32-39, 2014

[4]. D. K. Sari, A. Sundaryono, and D. Handayani, "Uji Biofuel Hasil Perengkahan Metil Ester dari Limbah Cair Pabrik Minyak Kelapa Sawit Dengan Katalis MoNi/HZ," Alotrop, vol. 1, no. 2, 2017.

[5]. A. S. Irtawaty and M. Ulfah, "Alat Penjernih Minyak Goreng dan Pembuatan Biodiesel Otomatis Menggunakan Metode K-Means Berbasis Arduino Mega 2560," in PROSIDING SNITT POLTEKBA, 2018, pp. $116-122$.

[6]. Sukarno, "Studi Pengaruh Pencampuran Aditif Terhadap Viskositas Biodiesel Pada Suhu Rendah," Universitas Diponegoro, 2012.

[7]. S. Kim, K. C. Kim, and E. Yeom, "Microfluidic method for measuring viscosity using images from smartphone," Opt. Lasers Eng., vol. 104, no. May, pp. 237-243, 2018.

[8]. A. H. Sarapardeh, S. M. J. Majidi, B. Mahmoudi, A. S. A. Ramazani, and A. H. Mohammadi, "Experimental measurement and modeling of saturated reservoir oil viscosity," Korean J. Chem. Eng., vol. 31, no. 7, pp. 1253-1264, 2014.

[9]. I. Panagiota, Kanaveli, M. Atzemi, and E. Lois, "Predicting The Viscosity of Diesel/Biodiesel Blends," Fuel, vol. 199, no. 1 July, pp. 248-263, 2017.

[10]. X. Meng, M. Jia, and T. Wang, "Neural network prediction of biodiesel kinematic viscosity at $313 \mathrm{~K}$," Fuel, vol. 121, no. 1 April, pp. 133-140, 2014.

[11]. J. . Tang, "Measurements of fluid viscosity using a miniature ball drop device," Rev. Sci. Instrum., vol. 87, no. $5,2016$. 